\title{
Optimizing operation of a large-scale pumped storage hydropower system coordinated with wind farm by means of genetic algorithms
}

\begin{abstract}
Bakanos P.I.* and Katsifarakis K.L. Greece

Received: 06/12/2018, Accepted: 31/01/2019, Available online: 05/02/2019

https://doi.org/10.30955/gnj.002978

Abstract

Due to the intermittent and fluctuating nature of wind and other renewable energy sources, their integration into electricity systems requires large-scale and flexible storage systems to ensure uninterrupted power supply and to reduce the percentage of produced energy that is discarded or curtailed. Storage of large quantities of electricity in the form of dynamic energy of water masses by means of coupled reservoirs has been globally recognized as a mature, competitive and reliable technology; it is particularly useful in countries with mountainous terrain, such as Greece. Its application may increase the total energy output (and profit) of coupled wind-hydroelectric systems, without affecting the availability of water resources.
\end{abstract}

Division of Hydraulics and Environmental Engineering, Department of Civil Engineering, A.U.Th, GR-54124 Thessaloniki, Macedonia,

*to whom all correspondence should be addressed: e-mail: p.bakanos@civil.auth.gr

Optimization of such renewable energy systems is a very complex, multi-dimensional, non-linear, multi modal, nonconvex and dynamic problem, as the reservoirs, besides hydroelectric power generation, serve many other objectives such as water supply, irrigation and flood mitigation. Moreover, their function should observe constraints such as environmental flow. In this paper, we developed a combined simulation and optimization model to maximize the total benefits by integrating wind energy production into a pumped-storage multi-reservoir system, operating either in closed-loop or in open-loop mode. In this process, we have used genetic algorithms as the optimization tool.

Our results show that when the operation of the reservoir system is coordinated with the wind farm, the hydroelectricity generation decreases drastically, but the total economical revenue of the system increases by $7.02 \%$ when operating in closed-loop and by $7.16 \%$ when operating in open-loop mode. We conclude that the hydro-wind coordination can achieve high wind energy penetration to the electricity grid, resulting in increase of the total benefits of the system. Moreover, the open-loop pumped-storage multi-reservoir system seems to have better performance, ability and flexibility to absorb the wind energy decreasing to a lesser extent the hydroelectricity generation, than the closed-loop.

Keywords: Pumped-storage hydropower plant, multireservoir systems, wind farm, optimization, genetic algorithms.

\section{Introduction}

In recent years, under the pressure of global warming and the resulting climate change, significant effort has been made worldwide to reduce dependence on fossil fuels (i.e. coal, oil and natural gas). In this effort to shift to a low-carbon society, renewable energy sources such as wind, sun, water, biomass and geothermal heat play a key role, mainly for three reasons: a) their environmental impact is rather low b) they are practically inexhaustible and c) they are more evenly distributed around the globe.

While renewable energy is the key to sustainable development and to improvement of overall energy security, its penetration to the energy market is curtailed by some features of the respective sources. The most prominent one is that energy generated from most of them, such wind turbines and photovoltaic stations, is intermittent and fluctuating, resulting in instabilities of electrical systems. In order to promote their use on a large scale, drastically upgraded flexible and stable systems are required (E-Storage, 2016). In this effort, efficient storage of electricity is of prime importance, in order to match energy production with demand. For this reason, large-scale energy storage techniques attract great interest around the world. Among the alternative energy storage technologies, especially in large-scale applications, the Pumped Hydro Storage Power Plant (PHSPP) is the most mature and efficient, allowing for improved elasticity and efficiency of the energy system (stoRE, 2014). Moreover, it is suitable for autonomous power systems with high levels of renewable generation (Kaldellis, 2010). The equipment of a PSHPP has an additional feature, compared to that of a conventional hydropower plant (HPP): besides producing electricity, it can also consume it. The reason is the following: PSHPP 
operation is based on the storage of energy in the form of water pumped from a lower elevation tank to a higher elevation one, using excess energy produced by external green sources (or even by conventional ones), which, without storage, is wasted during low demand hours. These facilities provide very large capacity of electricity, with low operation cost and high reliability. Pumpingstorage facilities also provide ancillary network services, such as network frequency control and reserve creation. This is due to the ability of pumping and storage facilities of the hydroelectric plants, to respond to load changes within a few seconds (Pérez-Díaz et al., 2015).

\section{Literature review}

Over the last few years, many new techniques have been developed to improve controllability of the output of wind parks and to facilitate its interaction with the energy power market. Some of them concentrated to the issue of increasing the penetration of renewable energy in power systems as an economical issue, while others on compensation of wind farm output power fluctuations. Kaldellis et al. (2002) investigated the long-term economic viability of the operation of a wind park cooperating with two water reservoirs, involving a micro-hydroelectric power plant and a water pump station. The objective was to store the energy generated by the wind park during low demand periods. Castronuovo and Lopes (2004) proposed the utilization of water storage ability to improve wind park operational economic gains and to attenuate the active power output variations due to the intermittence of the wind-energy resource. They developed an hourlydiscretized optimization algorithm approach to identify the best-combined daily operation strategy to be adopted in a wind and small hydro generation/pumping facility, provided that wind-power forecasting is available. Based on their results, they concluded that the use of a hydrological storage facility increases profits and controllability of the generation output of the wind park; moreover, it improves the participation of wind generation in electricity markets.

Later, Matevosyan and Söder (2007) considered a multireservoir hydropower system coordinated with wind power in areas with congestion problems, considering the uncertainty of wind power forecasts and power market prices. The developed day-ahead planning algorithm was tested in a case study and showed that the coordination of wind power and hydropower can be beneficial, because it greatly decreases wind energy curtailments and leads to a more efficient utilization of the existing transmission lines, without any negative economical impact on the hydropower or wind power utility. In their work GarciaGonzalez et al. (2008) investigated the combined optimization of a wind farm and a pumped-storage facility from the point of view of a generation company in a market environment by a two-stage stochastic programming approach. They formulated a two-stage stochastic optimization problem with two random parameters: prices and wind generation and they concluded that the method can be an effective way to model the real decision-making process that wind park operators face in a spot-market framework under uncertainty.

A wind-hydro-pumped storage hybrid power in Ikaria, Greece, was presented by Papaefthymiou et al. (2010). They introduced a suitable operating policy and the results from the simulation showed a significant increase in the penetration of renewable energy resources in the island's energy balance, which may exceed $50 \%$ on an annual basis. In addition, the hybrid system efficiently exploits the available wind and hydropower potential and can provide stable capacity on the island system, by replacing expensive conventional peak units.

A mixed-integer linear programming approach is presented by Cruz et al. (2014) for the optimal scheduling and operation of a pumped-hydro system with a wind farm to maximize profit in a day-ahead market. The approach addressed was tested in case studies, which proved the effectiveness of the proposed approach to decrease wind energy curtailments and avoid penalty risks related to energy deviations. Kumar et al. (2016) developed an hourly optimization approach to find the optimum operation strategy of hydro generation and pumping for a small-scale hydro system. Pumped storage plant was added to electricity system to achieve high economic gain from wind energy system, having variable and intermittent characteristics and the results showed a significant increase to the predicted yearly average economic gain.

In their work, Chalakatevaki et al. (2017) evaluated various energy resources using technical, environmental and economic criteria with emphasis to biomass, pumped hydro storage and replacement of oil power plants. They presented a synthesis as toy-model that satisfies the electric energy demand including base and peak electric loads in Astypalaia, which is one of the Dodecanese islands, Greece. Bakanos and Katsifarakis (2018a) presented an optimal operation scheduling for a day ahead of an open-loop multi-reservoir pumped storage system with a wind farm connected to the grid. The results showed that the hydro wind coordination can achieve high penetration of wind power to the power system and greater economic benefits.

\section{Genetic algorithms}

\subsection{Outline of the method}

The method of Genetic algorithms (GAs) is a mature heuristic optimization technique, which is used extensively in water resources management problems (e.g. Katsifarakis, 2012). It was initially developed by John Holland and his coworkers (Holland, 1975), it mimics the biological evolution and is based on Darwin's theory of survival of the fittest.

The typical binary genetic algorithm optimization process (e.g. Goldberg, 1989) starts by coding the values of the decision variables of the problem under consideration into a string of characters, which in analogy with the biological template, is called chromosome (or individual) and represents a solution to the problem. This is followed by 
the creation of the initial population, namely a number of chromosomes, usually randomly generated. These individuals are evaluated and assigned a "fitness value", on the basis of mathematically formulated criteria, called fitness function or process. This process may include penalties, which reduce the chromosome's fitness, if it represents a solution that violates constraints of the problem. Then the next generation is created with the help of three key operators (possibly additional ones) that mimic biological processes.

First, the selection operator is used, offering to better chromosomes a higher chance of survival and reproduction. The most popular selection techniques are the biased roulette wheel and the tournament. As these methods do not fully guarantee that the best chromosome of one generation will pass to the next one, an additional process, called elitism is incorporated in many codes. Then the crossover operator is applied, with which offspring are formed from two existing chromosomes, exchanging randomly parts thereof. The basic idea is that at least one of the new chromosomes could be better than both parents, if it includes some of their best features. Finally, the mutation operator, which alters some of the characters (genes), namely chromosome digits, introduces new genetic structures and adds some additional variability and diversity to the population. Mutation helps the algorithm not to be trapped by local optima and to reach the global ones. This process (evaluation of chromosomes and implementation of operators) is repeated for a number of generations, determined from the beginning or resulting from a termination criterion. It is expected that in the last generation the optimal, or at least a very good solution to the problem, will have been reached.

\subsection{Application of $G A$ to the optimization of the operation of multi-purpose multi-reservoir systems}

The first who used the method of GAs in the multireservoir optimization were Esat and Hall (1994), who applied a GA code to the four-reservoir problem. The objective was to maximize the benefits from power generation and irrigation water supply, subject to constraints on storages and releases from the reservoirs. In their paper, they showed the significant potential of GAs in water resources systems optimization, and clearly demonstrated the advantages of GAs over standard dynamic programming (DP) techniques in terms of computational requirements. Oliveira and Loucks (1997) used a GA to evaluate operating rules for multi-reservoir systems, demonstrating that GAs can be used to identify effective operating policies. Significant benefits were perceived to lie in the freedom afforded by GAs in the definition of operating policies and their evaluation. Wardlaw and Sharif (1999) used GAs to a deterministic finite horizon multi-reservoir system operation and concluded that the approach can be easily applied to nonlinear and complex systems.

Gil et al. (2003) used GAs to deal with the short-term generation scheduling problem for hydrothermal systems and they demonstrated that the method has excellent performance in dealing with this kind of problem, obtaining near-optimal solutions in reasonable times and without sacrificing the realism of the electric and economic models. Zoumas et al. (2004) presented a GAs solution approach to the hydrothermal coordination problem of the Greek Power System, comprising 13 hydro plants and 28 thermal units. The results of the application of the proposed solution to the operation scheduling demonstrated the effectiveness of the proposed algorithm.

Hincal et al. (2011) explored the efficiency and effectiveness of the GAs to maximize the energy production of three reservoirs in the Colorado River Storage Project in USA. Xu et al. (2012) proposed modified GA using stochastic operators within the feasible region of variables in the operation of a multi-reservoir system consisting of five reservoirs. The performance of the proposed GA was evaluated by comparing its results with those of the traditional GAs and it was found that it improves the refinement of the quality of a solution in a more efficient and robust way.

loannou et al. (2013) used stochastic analysis and simulation of hydro meteorological processes for optimizing hybrid renewable energy systems. They performed stochastic simulation of an autonomous hypothetical hybrid renewable energy system and optimized its performance using GAs. Moreover, they optimized the sizing of the system in order to satisfy the energy demand with high reliability and to minimize the cost. Bakanos and Katsifarakis (2018b) used GAs to maximize the hydroelectric energy of the multi-reservoir system at Aliakmon River, in Western Macedonia, Greece. Three different hydrological scenarios dry, average and wet year were considered and evaluated. Based on the results, they suggested a general operating rule for the large reservoirs of the system.

\section{Optimal operation scheduling of a PSHPP with wind farm using genetic algorithms}

In this paper, we present a tool to design the optimal configuration of a wind farm combined with a pumped storage hydro-plant, which operates either in closed or in open-loop form. The optimal generation scheduling of a hydro pump wind system aims at the utilization of water storage ability to improve wind farm operational financial gains and to attenuate the active power output variations due to the intermittence of the wind-energy resource. The short-term hydro-wind scheduling suggests that current market mechanisms are inducing electricity supply companies to generate water flows as large as possible, namely to profit from selling electricity, when prices are higher and to pay for pumping as little as possible when prices are low and the wind is high. At times of low electrical demand and high wind energy production, electric power is used to pump water into the upper reservoir, so the excess of the wind energy can be stored and not discarded. During periods of high electrical demand, water is released back into the lower reservoir through a turbine, thereby generating electricity. 
Considering the conversion losses of the pumping process and evaporation losses, a maximum of $70 \%$ to $85 \%$ of the electrical energy used to pump the water into the upstream reservoir can be regained.

\subsection{Problem formulation and case study}

In the present study, we consider a two-reservoir cascade system with hydropower plants in series into a river, and a wind farm as well, as shown in Figure 1. The pumped storage upstream plant has three reversible pump turbines and is located at the level of the downstream reservoir. The second hydro power plant has three turbines for electricity generation. The hydropower plants are coordinated and cooperate with the wind park and are connected to the grid. The task is to maximize the financial benefits from operating the system over a 24-hour horizon. The objective function shown in Equation 1, is to maximize the profit from selling energy ( $\left.S E_{\text {grid }}\right)$ to the electric grid:

$\operatorname{MaxSE} E_{\text {grid }}=\sum_{t=1}^{t=24} c_{i} \cdot P_{\text {grid }, t} \cdot t$

The maximization of the objective function of the shortterm pumped storage hydro wind scheduling problem is subject to a number of constraints. Due to the short time horizon of the simulation, environmental flow will not be taken into account in the model, as it is separately ensured for the reservoir system. The operation constraints are summarized in equations 2-15 as follows:

a) System active power balance

$P_{\text {grid }, t}=P_{w, t}+P_{1, t}+P_{2, t}$

The power supplied to the interconnected grid is composed of the hydropower generation plus the wind power production, in each interval. If the PSHPP 1 is in pump mode at time $t$, it consumes power and the term $P_{1}$, $\mathrm{t}$ in Equation 2 is negative. The hydropower from the two reservoirs is calculated by Equation 3 and the net head is calculated by Equation 4:

$P_{\text {hydro }_{i, t}}(\mathrm{MW})=\frac{n_{i} \cdot \rho \cdot g \cdot Q_{i, t} \cdot \text { Hnet }_{i, t}}{1000}$

$H_{n e t i, t}=H F_{i, t}-H T_{i, t}-k_{i} Q_{i, t}{ }^{2}$

When the PSHPP 1 is in pump mode, the pump power is calculated by Equation 5 and the pump head is calculated by Equation 6:

$P_{\text {pump }_{1, t}}(\mathrm{MW})=\frac{\rho \cdot g \cdot Q_{\text {pump }_{1, t}} \cdot H_{\text {pump }}}{1, t}$

$H_{\text {pump1,t }}=H F_{1, t}-H_{1, t}+k_{i} Q_{p u m p 1, t}{ }^{2}$

b) Hydropower plants generation or pumping limits:

Phydroi,min $\leq$ Phydroi, $\leq$ Phydroi, max

$P_{\text {pump1,min }} \leq P_{\text {pump1, }} \leq \mathrm{P}_{\text {pump1, }}$ max

c) Wind farm generation limits:

$0 \leq P_{w, t} \leq P_{w, \max }$ d) The maximum allowable power exchange with the system is limited by the features of the transmission line, which is considered as fixed during all $24 \mathrm{~h}$ periods:

$P_{\text {grid, }, t} \leq 800 \mathrm{MW}$

e) Dynamic water balance in reservoirs or equation of continuity:

$\mathrm{V}_{\mathrm{i}, \mathrm{t}+1}=\mathrm{V}_{\mathrm{i}, \mathrm{t}}+\mathrm{l}_{\mathrm{i}, \mathrm{t}}-\mathrm{Q}_{\mathrm{i}, \mathrm{t}}$

f) Maximum and minimum volume levels of reservoirs:

$\mathrm{V}_{i, \min } \leq \mathrm{V}_{\mathrm{i}, \mathrm{t}} \leq \mathrm{V}_{\mathrm{i}, \max }$

g) Lower and upper discharge limits of the turbines:

$\mathrm{Q}_{\mathrm{i}, \min } \leq \mathrm{Q}_{\mathrm{i}, \mathrm{t}} \leq \mathrm{Q}_{\mathrm{i}, \max }$

h) Lower and upper discharge limits of the pump mode:

Qpump1,min $\leq$ Qpump1,t $\leq$ Qpump1,max

i) Initial and final reservoir storage volume condition:

$\mathrm{V}_{\mathrm{i}, 12}=\mathrm{V}_{\mathrm{i}, 0}$

The symbols in Equations 1 to 15 are explained below:

$\mathrm{c}_{\mathrm{i}}$ : spot electricity price at time $\mathrm{t}\left(€ \mathrm{MWh}^{-1}\right)$

g: gravity acceleration $\left(9.81 \mathrm{~m} \mathrm{sec}^{-2}\right)$

$\mathrm{HF}_{\mathrm{i}, \mathrm{t}}$ : forebay elevation of the HPP $\mathrm{i}$ at time $\mathrm{t}(\mathrm{m})$

Hneti,t: net head of the HPP i at time $t(m)$

Hpump1,t: pumping head of the PSHPP 1 at time $t(m)$

$\mathrm{HT}_{\mathrm{i}, \mathrm{t}}$ : tailrace elevation of the HPP $\mathrm{i}$ at time $\mathrm{t}(\mathrm{m})$

$\mathrm{i}$ : reservoir or HPP $\mathrm{i}$ index, $\mathrm{i}=1,2$

$l_{i, t}$ inflow in the reservoir $i$ at time $t\left(\mathrm{~m}^{3} \mathrm{sec}^{-1}\right)$

$k_{i}$ : friction coefficients of penstocks of the HPP i $\left(s^{2} \mathrm{~m}^{-5}\right)$

$\mathrm{n}_{\mathrm{i}}$ : overall hydro generation efficiency factor for HPP $\mathrm{i}$

$\mathrm{n}_{\text {pump1: }}$ overall pumping efficiency for PSHPP 1

Prid,t: power injected into the electrical grid at time $t$ (MW)

$\mathrm{P}_{\mathrm{i}, \mathrm{t}}$ : power output of HPP $\mathrm{i}$ at time $\mathrm{t}(\mathrm{MW})$

$\mathrm{P}_{\mathrm{w}, \mathrm{t}}$ : available wind power output of wind farm at time $t$ (MW)

$Q_{i, \max }, Q_{i, \min }$ : turbine discharge limits for i HPP $\left(\mathrm{m}^{3} \mathrm{sec}^{-1}\right)$

$\mathrm{Q}_{\mathrm{i}, \mathrm{t}}$ : discharge through hydro turbines i HPP $\left(\mathrm{m}^{3} \mathrm{sec}^{-1}\right)$

Qpump1,max, Q1pump,min: pump discharge limits for the upper PSHPP $1\left(\mathrm{~m}^{3} \mathrm{sec}^{-1}\right)$

$\mathrm{t}$ : time interval $(h), t=1 ; 2, \ldots, 24$

$\mathrm{V}_{\mathrm{i}, \max }, \mathrm{V}_{\mathrm{i}, \min }$ : max, min volume limits of reservoir $\mathrm{i} \cdot\left(\mathrm{hm}^{3}\right)$

$V_{i, t}$ : water volume of reservoir $i$ at time $t\left(\mathrm{hm}^{3}\right)$

$\rho:$ water density $\left(1000 \mathrm{~kg} \mathrm{~m}^{-3}\right)$ 


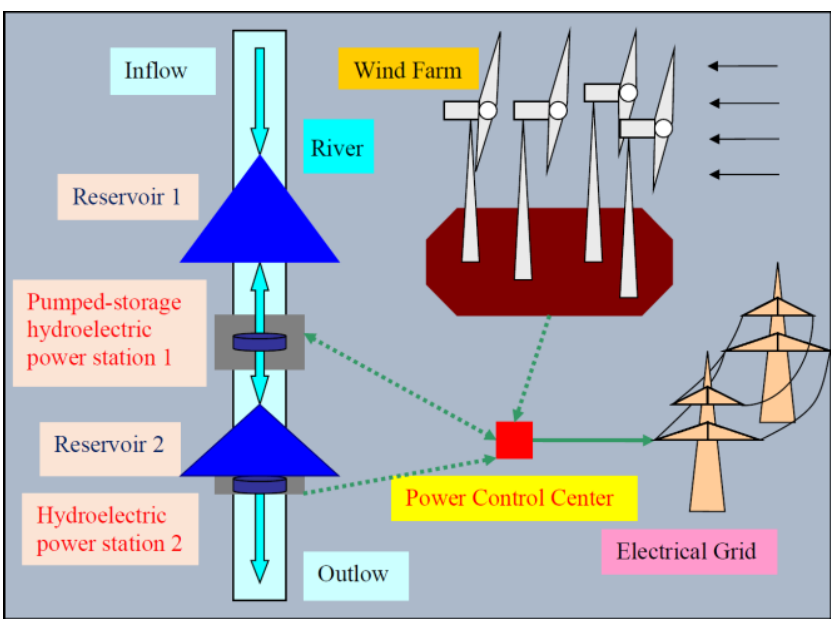

Figure 1. The system of reservoirs and the wind farm (Generated by the authors)

\subsection{Hydropower plants}

The technical and operational characteristics of reservoirs and hydropower facilities are summarized in Table 1, while the relationship between elevation and storage volume is shown in Figure 2. In the first case where the system is operating in closed-loop mode there are no water inflows and outflows. In the second case (namely in open-loop mode) the first reservoir has natural inflow $\mathrm{I}_{1, \mathrm{t}}=0.30 \mathrm{hm}^{3} \mathrm{~h}^{-1}\left(166.67 \mathrm{~m}^{3} \mathrm{sec}^{-1}\right)$ and the second has no natural inflow and $\mathrm{I}_{2, \mathrm{t}}=\mathrm{Q}_{1, \mathrm{t}}$

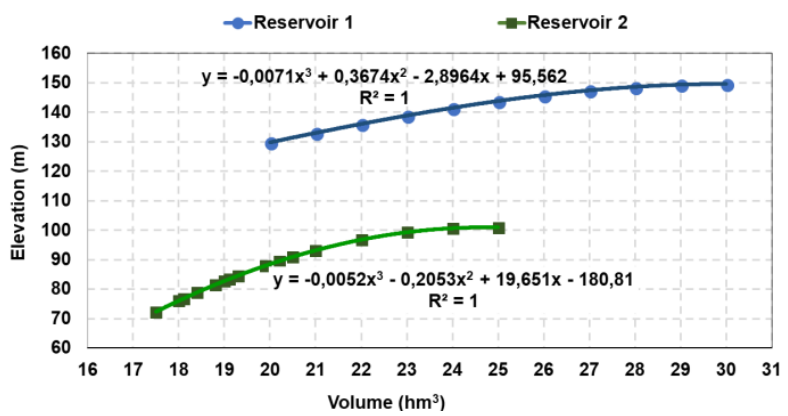

Figure 2. Reservoirs water level versus volume

\subsection{Wind power}

The wind speed is always fluctuating, and thus the energy content of the wind is always changing. The variation depends both on the weather and on local surface conditions and obstacles. Energy output from a wind turbine will vary as the wind varies, although the most rapid variations will to some extent be compensated for by the inertia of the wind turbine rotor (Wagner, 2018). In order to investigate the benefits of coordination between hydro and wind energy production, we have taken into account that the installed capacity of the wind farm is $P_{w, m a x}=1000 M W$, namely more than twice the installed capacity of the hydropower plants (468MW), as in similar studies (Kumar et al., 2016). The wind power forecast is available for the day-ahead and serves as input, as shown in Figure 3. The theoretical maximum total energy output of the wind farm in standalone mode is $14300 \mathrm{MWh}$ and the maximum profit is $745000.00 €$.

\subsection{Electricity market price}

The $24 \mathrm{~h}$ day-ahead hourly energy price forecast of the electricity market is shown in Figure 4.

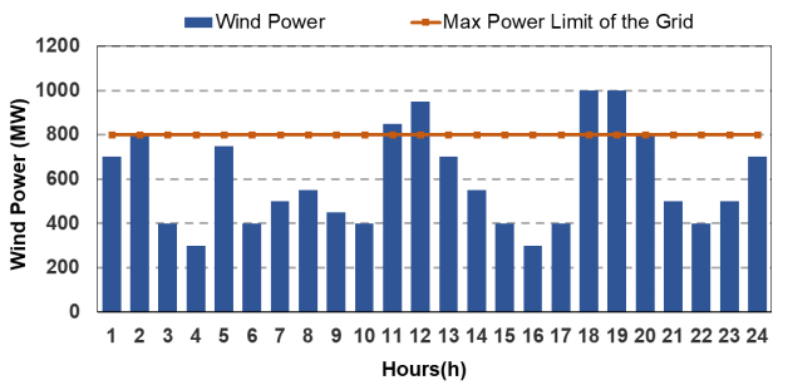

Figure 3. Wind power profile and power limit of the grid

Table 1. Technical and operational characteristics of reservoirs and hydropower facilities

\begin{tabular}{|c|c|c|c|}
\hline & & Reservoir 1 & Reservoir 2 \\
\hline \multicolumn{2}{|c|}{ Initial/Final volume $\left(\mathrm{hm}^{3}\right)$} & $25 / 25$ & $21.25 / 21.25$ \\
\hline \multicolumn{2}{|c|}{ Maximum/Minimum volume operation level $\left(\mathrm{hm}^{3}\right)$} & $30 / 20$ & $25 / 17.5$ \\
\hline \multicolumn{2}{|c|}{ Maximum/Minimum generation release $\left(\mathrm{hm}^{3} \mathrm{~h}^{-1}\right)$} & $1.20 / 0.12$ & $1.20 / 0.12$ \\
\hline \multicolumn{2}{|c|}{ Maximum/Minimum pumping release $\left(\mathrm{hm}^{3} \mathrm{~h}^{-1}\right)$} & $1.20 / 0.20$ & - \\
\hline Head vs Volume curve & $a_{i}$ & -0.0071 & -0.0052 \\
\hline \multirow[t]{3}{*}{$H_{i}(m)=a_{i} V_{i}^{3}+b_{i} V_{i}^{2}+c_{i} V_{i}+d_{i}$} & $b_{i}$ & 0.3674 & -0.2053 \\
\hline & $\mathrm{c}_{\mathrm{i}}$ & -2.8964 & 19.651 \\
\hline & $d_{i}$ & 95.562 & -180.81 \\
\hline \multicolumn{2}{|c|}{ Maximum/Minimum forebay level $(\mathrm{m})$} & $149.63 / 129.79$ & $100.90 / 72.34$ \\
\hline \multicolumn{2}{|c|}{ Maximum/Minimum tailrace level $(\mathrm{m})$} & $100.9 / 72.34$ & $20 / 20$ \\
\hline \multicolumn{2}{|c|}{ Discharge/Pumping efficiency } & $0.88 / 0.85$ & 0.88 \\
\hline \multicolumn{2}{|c|}{ Friction coefficients of penstock $\left(\mathrm{sec}^{2} \mathrm{~m}^{-5}\right)$} & 0.00003 & 0.00007 \\
\hline \multicolumn{2}{|c|}{ Generation/Pumping capacity power (MW) } & $231(3 \times 77) / 300(3 \times 100)$ & $237(3 \times 79)$ \\
\hline
\end{tabular}




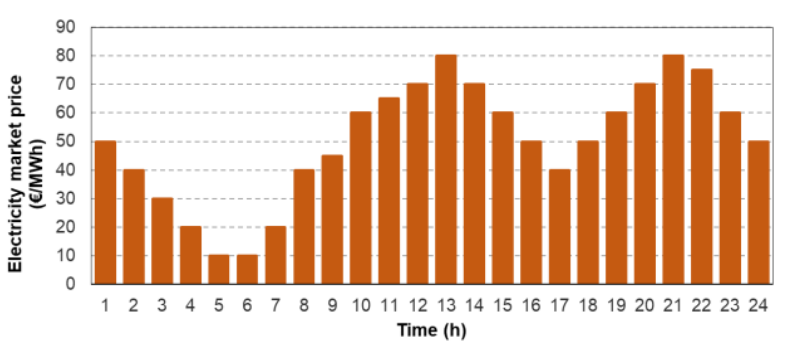

Figure 4. Forecasted market prices of electricity for $24 \mathrm{~h}$ ahead

\section{First case study: pumped storage hydropower system operating in closed-loop mode}

5.1. Optimization results in closed-loop operation mode of pumped storage hydropower system without wind farm coordination

Results obtained by optimizing the multi-reservoir system independently of the wind farm are shown in Table 2. The pumped storage hydropower station 1 pumps when the spot price is low until the downstream reservoir empties and produces when the spot price and the specific energy for generation is high, as shown in Figures 5 and 6. Obviously, it consumes more energy than it produces, but even though the net energy is negative by $-202.87 \mathrm{MWh}$, the total hydroelectric revenue is positive at $45455.35 €$, because the multi-reservoir system is taking advantage of the storage and the fluctuation in the market price of the grid.

Adding the power of the wind farm to the hydropower, the total power exceeds the maximum capacity of the transmission line to the grid and $9.73 \%$ of the energy is discarded, as shown at the diagram of Figure.7. The wind energy that can be absorbed by the system is 12908.71MWh from the 14300MWh and the discarded energy is $1391.29 \mathrm{MWh}$, which means $90.27 \%$ penetration of wind energy into the grid. The financial revenue from wind energy is $660552.90 €$, from hydropower $45455.35 €$ and the total profit is 706008.25€.

In uncoordinated operation benefit maximization from selling hydroelectric energy, depends only on the electricity market prices and does not take into account wind energy curtailment or discard, due to the technical limit. That's why at intervals 11:00 and 19:00 in Figure 7, hydropower production is large, as it is absorbed by the grid first, and independently of the size of wind energy production.

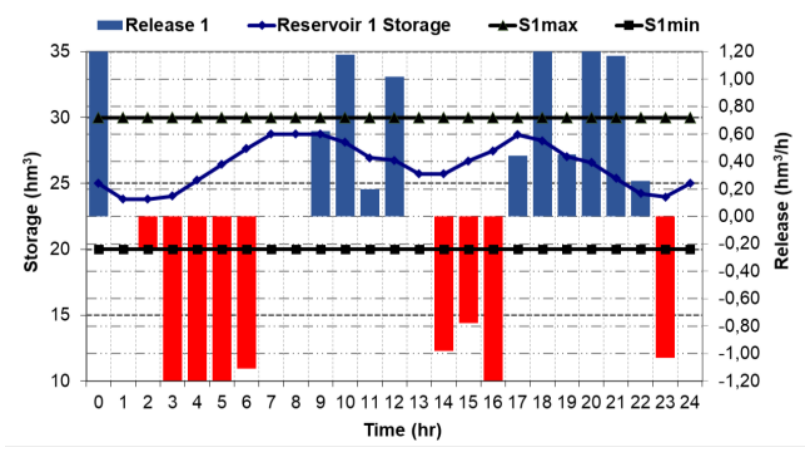

Figure 5. Reservoir 1 storage curve and release profile for operating in closed-loop mode without hydro-wind coordination

Table 2. Optimization results for operating in closed-loop mode without hydro-wind coordination

\begin{tabular}{cccccc}
\hline & PSHPP 1 & HPP 2 & Total Hydro energy & Wind Farm & System Energy \\
\hline Energy generation (MWh) & 1445.29 & 0 & 1445.29 & 14300.00 & 15745.29 \\
\hline Energy for pumping (MWh) & -1648.16 & 0 & -1648.16 & 0 & -1648.16 \\
\hline Energy discarded (MWh) & 0 & 0 & 0 & -1391.29 & -1391.29 \\
\hline Net energy (MWh) & -202.87 & 0 & -202.87 & 12908.71 & 12705.84 \\
\hline Economical Revenue $(€)$ & 45455.35 & 0 & 45455.35 & 660552.90 & 706008.25 \\
\hline
\end{tabular}

5.2. Optimization results in closed-loop operation mode of pumped storage hydropower system with wind farm coordination

Coordinating operation of the reservoir system and the wind farm, the optimization by GAs can balance the power output of the system and reduce the energy which is discarded, absorbing the excess power (over $800 \mathrm{MW}$ ) by pumping water from the downstream reservoir to the upstream one. The energy and the revenue by optimizing the hydro-system with genetic algorithms are shown in Table 3 and the release from the reservoirs and the storage in this case are shown in the diagrams of Figures 8 and 9.

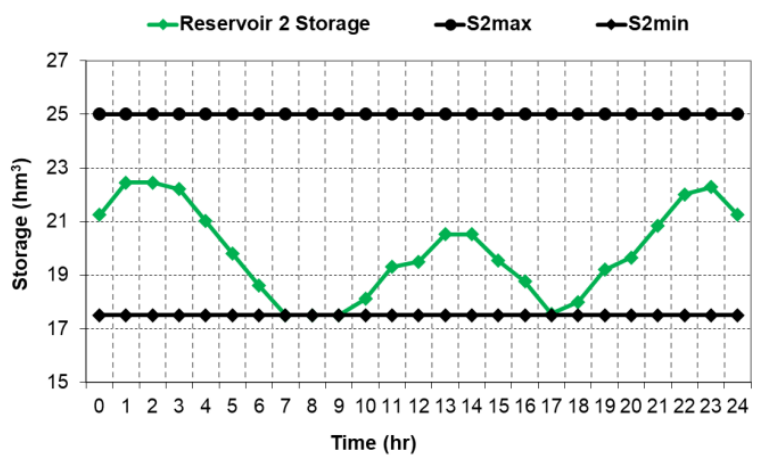

Figure 6. Reservoir 2 storage curve for operating in closed-loop mode without hydro-wind coordination 


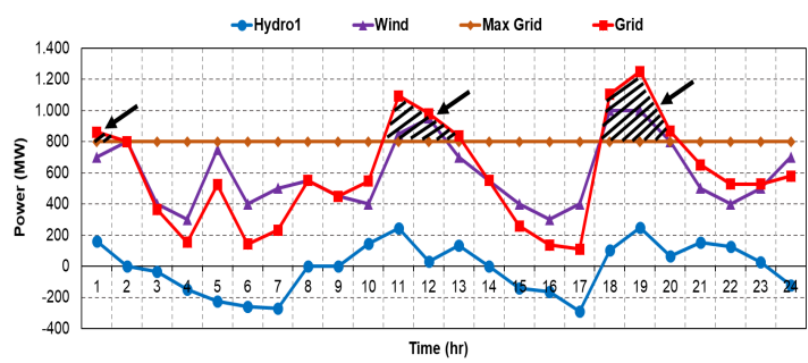

Figure 7. System power output diagram and the energy discarded for operating in closed-loop mode without hydro-wind coordination
The system can absorb all the 14300MWh (100\% penetration) of wind energy, as shown in the diagram of Figure 10 . The revenue with coordination from wind energy is $745000.00 €$ and from hydropower $10544.65 €$. The total hydroelectric revenue with coordination is about $76.80 \%$ smaller, because the wind power alters dynamically and drastically the operation of the reservoirs and the power transfer to the grid. The total economical revenue of the system is $755544.65 €$, namely $7.02 \%$ larger, compared to the case of uncoordinated function.

Table 3. Optimization results for operating in closed-loop mode with hydro-wind coordination

\begin{tabular}{cccccc}
\hline & PSHPP 1 & HPP 2 & Total Hydro energy & Wind Farm & System Energy \\
\hline Energy generation (MWh) & 936.88 & 0 & 936.88 & 14300.00 & 15236.88 \\
\hline Energy for pumping (MWh) & -1260.44 & 0 & -1260.44 & 0 & -1260.44 \\
\hline Energy discarded (MWh) & 0 & 0 & 0 & 0 & 0 \\
\hline Net energy (MWh) & -323.56 & 0 & -323.56 & 14300.00 & 13976.44 \\
\hline Economical Revenue $(€)$ & 10544.65 & 0 & 10544.65 & 745000.00 & 755544.65 \\
\hline
\end{tabular}

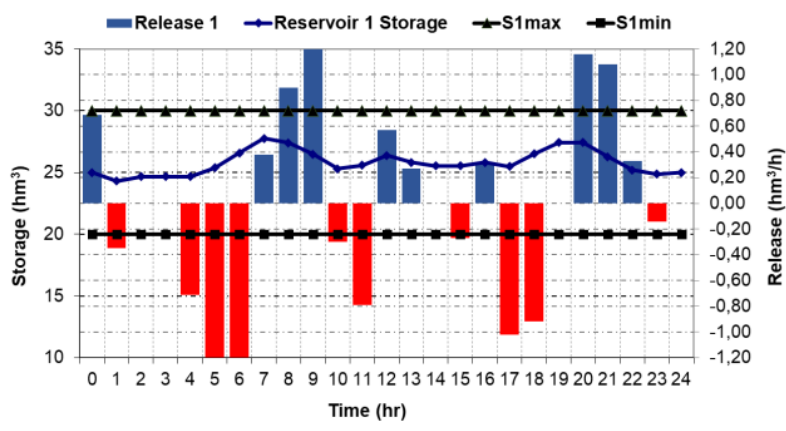

Figure 8. Reservoir 1 storage curve and release profile for operating in closed-loop mode with hydro-wind coordination

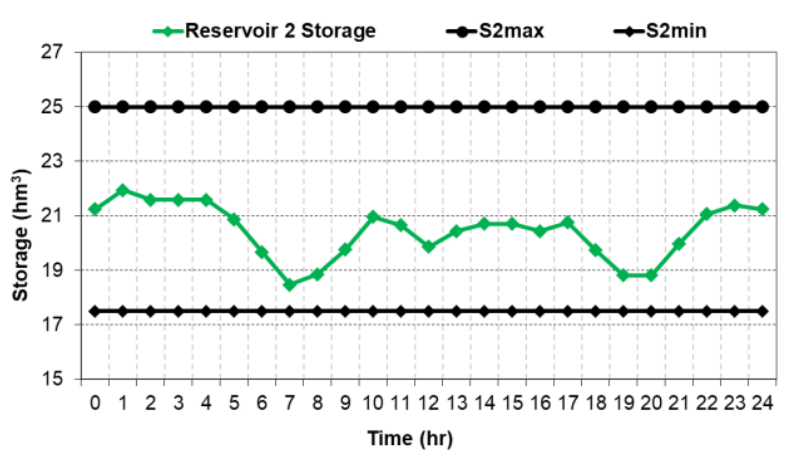

Figure 9. Reservoir 2 storage curve for operating in closed-loop mode with hydro-wind coordination

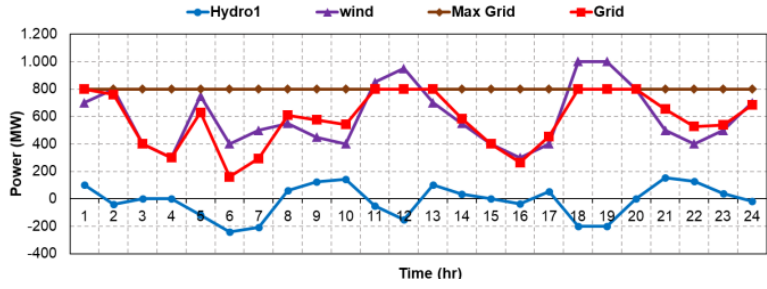

Figure 10. System power output diagram for operating in closedloop mode with hydro-wind coordination

\section{Second case study: pumped storage hydropower system operating in open-loop mode}

6.1. Optimization in open loop operation without coordination between wind farm and pumped storage hydropower system

Optimization results for the second case, where the reservoir system operates in open-loop mode and independently of the wind farm, are shown in Table 4 . The release from the reservoirs and the storage in this case are shown in the diagrams of Figures 11 and 12 . The upper reservoir is filling up early to the maximum volume, pumping from the downstream reservoir until it empties, taking advantage of the low spot price to achieve high specific energy for production at peak hours, namely from 10:00 to $15: 00$ and from 19:00 to 23:00. Then it releases continuously with high net head, more at peak hours, until it reaches the desired target volume. Summing up the wind farm power to the hydropower generation, the total electric power exceeds the maximum capacity of the grid 
and an amount of energy is discarded, as shown at diagram in Figure 13. The wind energy that can be absorbed by the system is $11713.71 \mathrm{MWh}$ out of the $14300 \mathrm{MWh}$ and the discarded energy is $2586.29 \mathrm{MWh}$, which means $81.91 \%$ penetration of wind energy into the grid. The financial revenue from wind energy is 581873.70€, from hydropower 273917.00€ and the total revenue is $855790.70 €$.

Table 4. Optimization results for operating in open-loop mode without hydro-wind coordination

\begin{tabular}{cccccc}
\hline & PSHPP 1 & HPP 2 & Total Hydro energy & Wind Farm & System Energy \\
\hline Energy generation (MWh) & 2210.77 & 2183.50 & 4394.27 & 14300.00 & 18468.91 \\
\hline Energy for pumping (MWh) & -225.36 & 0 & -225.36 & 0 & -225.36 \\
\hline Energy discarded (MWh) & 0 & 0 & 0 & -2586.29 & -2586.29 \\
\hline Net energy (MWh) & 1985.41 & 2183.50 & 4168.91 & 11713.71 & 15882.62 \\
\hline Economical Revenue $(€)$ & 134112.95 & 139804.05 & 273917.00 & 581873.70 & 855790.70 \\
\hline
\end{tabular}

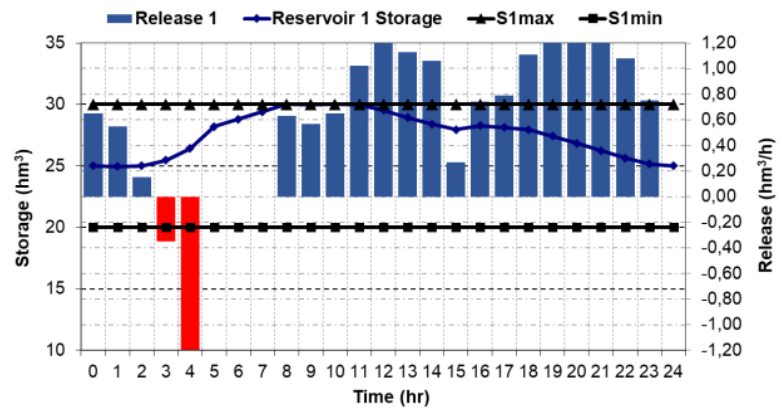

Figure 11. Reservoir 1 storage curve and release profile for operating in open-loop mode without hydro-wind coordination

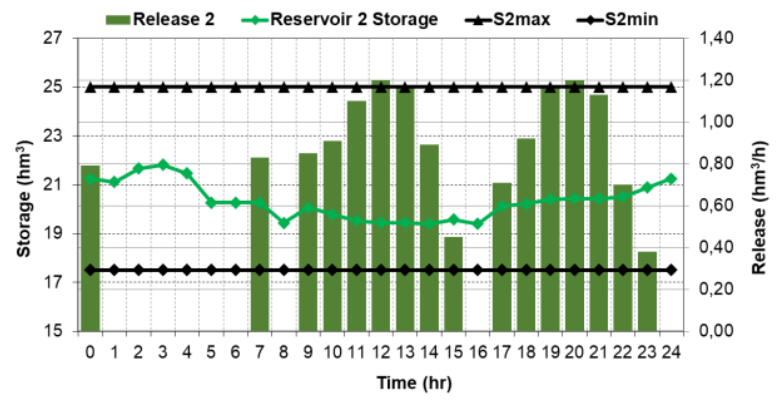

Figure 12. Reservoir 2 storage curve and release profile for operating in open-loop mode without hydro-wind coordination

\subsection{Optimization in open loop operation with coordination of wind farm and pumped storage hydropower system}

Coordinating operation in open-loop mode the reservoir system and the wind farm, the optimization by GAs can balance output of the system and reduce the energy which is discarded to zero, absorbing the excess power (over $800 \mathrm{MW}$ ) by pumping water from the downstream reservoir to the upstream one. In this case the maximum hydro energy power output by optimizing the hydrosystem with genetic algorithms is shown in Table 5. The release from the reservoirs and the storage in this case are shown in the diagrams of Figures 14 and 15. The system can absorb all the 14300MWh of wind energy, as shown in Figure 16, while the hydroelectric revenue from the hydropower stations this time is $37.19 \%$ lower. The revenue from wind energy in this case is $745000.00 €$ and from hydropower $172042.70 €$, summing to a total of $917042.70 €$, which means total increase by $7.16 \%$ compared to the case of uncoordinated function.

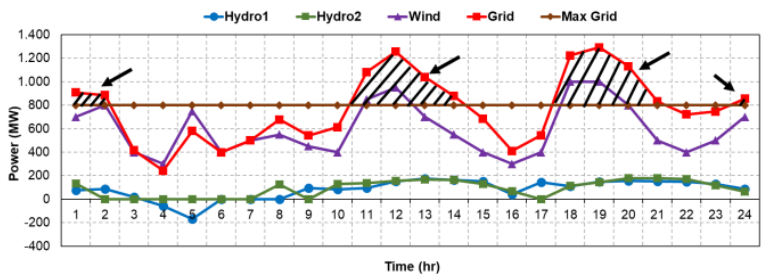

Figure 13. System power output diagram and the energy discarded for operating in open-loop mode without hydro-wind coordination

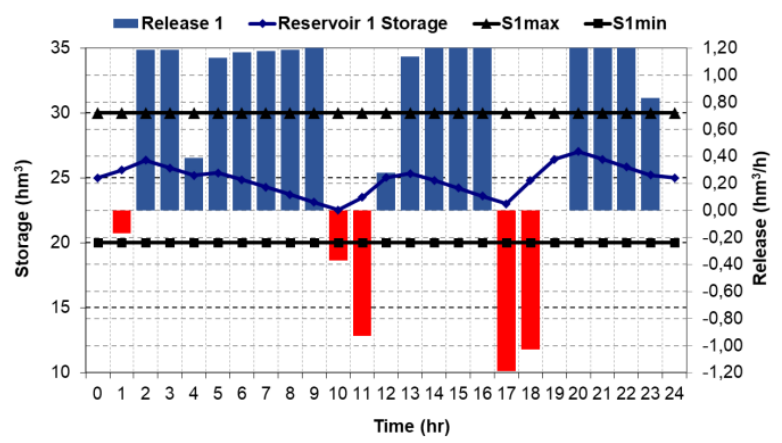

Figure 14. Reservoir 1 storage curve and release profile for operating in open-loop mode with hydro-wind coordination 
Table 5. Optimization results for operating in open-loop mode with hydro-wind coordination

\begin{tabular}{cccccc}
\hline & PSHPP 1 & HPP 2 & Total Hydro energy & Wind Farm & System Energy \\
\hline Energy generation (MWh) & 2078.24 & 2319.90 & 4398.14 & 14300.00 & 18698.14 \\
\hline Energy for pumping (MWh) & -633.10 & 0 & -633.10 & 0 & -633.10 \\
\hline Energy discarded (MWh) & 0 & 0 & 0 & 0 & 0 \\
\hline Net energy (MWh) & 1445.14 & 2319.90 & 3765.04 & 14300.00 & 18065.04 \\
\hline Economical Revenue & 62363.85 & 109678.85 & 172042.70 & 745000.00 & 917042.70 \\
\hline
\end{tabular}

benefit decreases by $37.19 \%$, but the total performance of

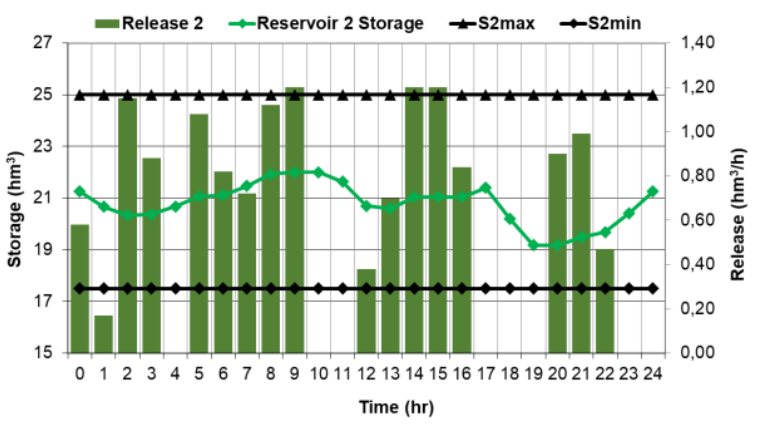

Figure 15. Reservoir 2 storage curve and release profile for operating in open-loop mode with hydro-wind coordination

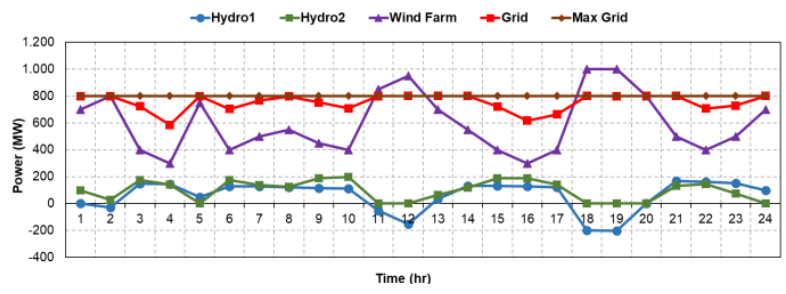

Figure 16. System power output diagram for operating in open-loop mode with hydro-wind coordination

\section{Conclusions}

In this work, an optimization approach based on genetic algorithms is developed for the optimal scheduling and operation strategy of a cascade two-reservoir system, which has a pumped-storage hydro power plant, a conventional hydro power plant and a wind farm. The aim is to maximize the financial benefits of operating the system over a 24-hour horizon in closed-and open-loop mode, with and without coordination.

In the first case study, when the reservoir system is operating in closed-loop mode, the results show that when there is no coordination with the wind farm, the economical revenue of the hydroelectricity generation is maximized, but $9.73 \%$ of the total wind energy is discarded or curtailed. When the system is coordinated with the wind farm, the hydroelectricity generation decreases significantly by $76.80 \%$ but all the wind energy is absorbed by the system, resulting in an increase of $7.02 \%$ of the total economic benefits. In the second case study, when the reservoir system is operating in openloop mode, the results show that when it is not coordinated with the wind farm, $18.09 \%$ of the wind energy is discarded. If the reservoir system is coordinated with the wind farm, the hydroelectricity generation the system increases about $7.16 \%$, mainly because all the wind energy is absorbed by the system.

Although the aforementioned percentages are casespecific, we can conclude that both closed-loop and openloop pumped-storage multi-reservoir systems coordinated with the wind farms and connected to the grid, can achieve larger economical benefits, than without coordination. Moreover, when the system is not coordinated, the major role to the storage has the variability of the spot price of the pool market, while when it is coordinated the storage depends on a combination of the fluctuations, the absorption of the wind power and the variability of the spot price. The results show that the open-loop pumped-storage system seems to have better performance, ability and flexibility to absorb the wind energy, since the hydroelectricity generation decreases to a lesser degree than the closedloop.

\section{References}

Bakanos P.I. \& Katsifarakis K.L. (2018a), Optimal operation scheduling of multipurpose pumped storage hydro power plant with high penetration of renewable energy resources, In: Protection and Restoration of the Environment XIV, July 36, Thessaloniki, Greece, 860-870.

Bakanos P.I. \& Katsifarakis K.L. (2018b), Development and evaluation of a decision-making system for optimal management of reservoirs in single time horizon, In: 11th National Conferences on Renewable Energy Sources, Institute of Solar Technology, Thessaloniki (in Greek).

Castruonovo E.D. \& Lopes J.A.P. (2004), On the optimization of the daily operation of a wind-hydropower plant, IEEE Transactions on Power Systems, 19(3), 1599-1606.

Chalakatevaki M., Stamou P., Karali S., Daniil V., Dimitriadis P., Tzouka K., Iliopoulou T. Koutsoyiannis D., Papanicolaou P. and Mamassis N. (2017), Creating the electric energy mix in a non-connected island, Energy Procedia, 125,425-434.

Cruz P., Pousinho H.M.I., Melício R. and Mendes V.M.F. (2014), Optimal coordination on wind-pumped-hydro operation, Conference on Electronics, Telecommunications and Computers - CETC 2013, Procedia Technology, 17, 445-451.

Esat V. \& Hall M.J. (1994), Water resources system optimisation using genetic algorithms, In: Proceedings of 1st international conference on hydroinformatics, Balkema, Rotterdam, Netherlands, 225-231.

E-Storage (2016), World Energy Resources, World Energy Council.

Garcia-Gonazalez J., Muela R., Santos L. and Gonzalez A. (2008), Stochastic Joint Optimization of Wind Generation and Pumped-Storage Units in an Electricity Market, Power Systems, IEEE Transactions, 23(2), 460-468. 
Gil E., Bustos J. and Rudnick H. (2003), Short-term hydrothermal generation scheduling model using a genetic algorithm, IEEE Transactions on Power Systems, 18(4), 1256-1264.

Goldberg D.E. (1989), Genetic algorithms in search, optimization and machine learning, Addison-Wesley, Reading, Mass.

Hinçal O., Altan-Sakarya A.B. and Ger A.M. (2011), Optimization of multireservoir systems by genetic algorithm, Water Resources Management, 25(5), 1465-1487.

Holland J.H. (1975), Adaptation in Natural and Artificial Systems, University of Michigan Press, Ann Arbor.

Ioannou X., Tsekouras G., Efstratiadis A. and Koutsoyiannis D. (2013), Stochastic analysis and simulation of hydrometeorological processes for optimizing hybrid renewable energy systems, In: Proceedings of the 2nd Hellenic Conference on Dams and Reservoirs, Athens, Greece.

Kaldellis J.K. (2010), Stand-Alone and Hybrid Wind Energy Systems, Technology, Energy Storage and Applications, Woodhead Publishing.

Kaldellis J.K., Kavadias K.A. and Vlachou D.S. (2002), Electricity load management of APS using wind-hydro solution, In: 3rd Mediterranean Conference and Exhibition on Power Generation, Transmission Energy and Distribution, Athens, Greece.

Katsifarakis K.L. (2012), Hydrology, Hydraulics and Water Resources Management: A Heuristic Optimization Approach, WIT Press.

Kumar M., Saini P. and Kumar N. (2016), Optimization of WindPumped Storage Hydro Power System, International Journal of Engineering Technology, Management and Applied Sciences, 4(4), ISSN 2349-4476.

Matevosyan J. \& Söder L. (2007), Short-term Hydropower Planning Coordinated with Wind Power in Areas with Congestion Problems, Wind Energy, 10(3), 195-208.

Oliveira R. \& Loucks D.P. (1997), Operating rules for multireservoir systems, Water Resources Research, 33(4), 839-852.

Papaefthymiou S.V., Karamanou E.G., Papathanassiou S.A. and Papadopoulos M.P. (2010), A Wind-Hydro-Pumped Storage Station Leading to High RES Penetration in the Autonomous Island System of Ikaria, IEEE Transactions on sustainable energy, 1(3), 163-172.

Pérez-Díaz J.I., Chazarra M., García-González J., Cavazzini G. and Stoppato A. (2015), Trends and challenges in the operation of pumped-storage hydropower plants, Renewable \& Sustainable Energy Reviews, 44, 767-784.

stoRE (2014), Final Publishable Report, Intelligent Energy Europe (IEE).

Wagner H.J. \& Mathur J. (2018), Introduction to Wind Energy Systems Basics, Technology and Operation, Springer.

Wardlaw R. \& Sharif M.(1999), Evaluation of genetic algorithms for optimal reservoir system operation, Journal of Water Resources Planning and Management, ASCE, 125(1), 25-33.

Xu B., Zhong P., Wan X., Zhang W. and Chen X. (2012), Dynamic feasible region genetic algorithm for optimal operation of a multi-reservoir system, Energies, 5(12), 2894-2910.

Zoumas C.E., Bakirtzis A.G., Theocharis J.B. and Petridis V. (2004), A genetic algorithm solution approach to the hydrothermal coordination problem, IEEE Transactions on Power Systems, 19(3), 1356-1364. 